\title{
Treatment for right-sided intrathoracic kidney with congenital diaphragmatic hernia by combined thoracoscopic and laparoscopic approach: a case report and literature review
}

\author{
Mingming Yu \\ Shanghai Jiao Tong University https://orcid.org/0000-0001-9957-6568 \\ Fang Chen \\ Shanghai Jiaotong University: Shanghai Jiao Tong University \\ Sisi Wei \\ Shanghai Jiaotong University: Shanghai Jiao Tong University \\ Hua Xie ( $\square$ drxiehua@163.com ) \\ Shanghai Jiao Tong University
}

\section{Case report}

Keywords: intrathoracic kidney, congenital diaphragmatic hernia, combined thoracoscopic and laparoscopic approach, anatomical reposition, nephropexy

Posted Date: November 8th, 2021

DOI: https://doi.org/10.21203/rs.3.rs-1025661/v1

License: (1) This work is licensed under a Creative Commons Attribution 4.0 International License. Read Full License

Version of Record: A version of this preprint was published at Urology on February 1st, 2022. See the published version at https://doi.org/10.1016/j.urology.2022.01.035. 


\section{Abstract}

Background

Intrathoracic kidney (ITK) associated with congenital diaphragmatic hernia (CDH) is rare congenital anomaly and usually requires surgery. The surgical methods and approaches are diverse.

Case presentation

We reported a case of a 5-year-old boy who was diagnosed as right-sided ITK with CDH. Surgical treatment was performed by combined thoracoscopic and laparoscopic approach. Anatomical reposition of the right kidney and nephropexy were carried out under laparoscopy, and repair of the hernia was performed under thoracoscopy. The postoperative recovery was uneventful and long-term follow-up demonstrated normal function and development of the kidney.

Conclusion

Combined thoracoscopic and laparoscopic approach is minimally invasive and effective for treatment of ITK associated with $\mathrm{CDH}$. It provides better visualization of the diaphragmatic foramen and the hernia sac, and can achieve anatomical reposition and fixation of the ectopic kidney.

\section{Background}

Intrathoracic kidney (ITK) is a rare condition with a prevalence of less than $0.01 \%[1]$. ITK associated with Congenital diaphragmatic hernia (CDH) is extremely rare and occupies less than $0.25 \%$ of all ITK cases[2]. ITK with $\mathrm{CDH}$ usually requires surgical treatment that can be performed by different approaches. Thoracoscopic and laparoscopic approaches are minimally invasive, equally effective as open approaches, and with their own advantages and disadvantages. Although dozens of such cases have been reported in children, only six cases were treated by laparoscopic or thoracoscopic approach (Table 1)[3-8]. Only one of the six cases was on the right side that was treated by thoracoscopic approach, and none of them was given nephropexy. Here we report a case of right-sided ITK with CDH in a boy who was treated by combined thoracoscopic and laparoscopic approach. Reduction of the hernia sac and repair of the defect was performed under thoracoscopy, while anatomical reposition of the right kidney and nephropexy was achieved under laparoscopy. This combined approach provided better visualization of the diaphragmatic foramen and the hernia sac, and offered access to anatomical reposition and fixation of the ectopic kidney. To our knowledge, it was the first time to adopt a combined thoracoscopic and laparoscopic approach for treatment of ITK with $\mathrm{CDH}$. 
Table 1

Cases of ITK with CDH treated by thoracoscopic or laparoscopic approach in children.

\begin{tabular}{|c|c|c|c|c|c|c|c|}
\hline Author, year & Sex & Age & Side & Approach & $\begin{array}{l}\text { Treatment of } \\
\text { Kidney }\end{array}$ & $\begin{array}{l}\text { Follow } \\
\text { up }\end{array}$ & Outcome \\
\hline Mizzi[3], 2020 & female & $\begin{array}{l}24- \\
\text { day- } \\
\text { old }\end{array}$ & left & thoracoscopic & $\begin{array}{l}\text { reduced } \\
\text { retroperitoneally }\end{array}$ & 3 years & uneventful \\
\hline Boo[4], 2017 & female & $\begin{array}{l}\text { 6- } \\
\text { week- } \\
\text { old }\end{array}$ & left & thoracoscopic & ND & $\begin{array}{l}3 \\
\text { months }\end{array}$ & uneventful \\
\hline $\begin{array}{l}\text { Dhaou[5], } \\
2017\end{array}$ & female & $\begin{array}{l}\text { 2-year- } \\
\text { old }\end{array}$ & right & thoracoscopic & $\begin{array}{l}\text { mobilized near } \\
\text { normal }\end{array}$ & 2 years & uneventful \\
\hline $\begin{array}{l}\text { Padma[6], } \\
2014\end{array}$ & male & $\begin{array}{l}\text { 1-year- } \\
\text { old }\end{array}$ & left & thoracoscopic & ND & $\begin{array}{l}6 \\
\text { months }\end{array}$ & uneventful \\
\hline $\begin{array}{l}\text { Kawashima[7], } \\
2014\end{array}$ & male & $\begin{array}{l}\text { 2-year- } \\
\text { old }\end{array}$ & left & laparoscopic & $\begin{array}{l}\text { moved into } \\
\text { abdomen }\end{array}$ & 5 years & uneventful \\
\hline Tillig[8], 2009 & female & $\begin{array}{l}\text { 6- } \\
\text { month- } \\
\text { old }\end{array}$ & left & laparoscopic & $\begin{array}{l}\text { positioned } \\
\text { retroperitoneally }\end{array}$ & ND & uneventful \\
\hline
\end{tabular}

\section{Case Presentation}

A 5-year-old boy was diagnosed with $\mathrm{CDH}$ incidentally two years ago in our hospital. His parents demanded conservative treatment initially as he was asymptomatic. Regular follow-up was done and the recent chest radiography revealed gas density shadows under the diaphragm (Figure 1a). Ultrasonography was performed subsequently and the result showed that the right kidney and part of the intestine herniated into the thoracic cavity (Figure 1b). Thus, he was admitted to the hospital for further treatment. Physical examination showed decreased respiratory sounds in the right lower lung and bowel sounds in liver area. The contents of hernia were confirmed by contrasted tomography. In addition, the right kidney was transposed with the renal hilum downward and the renal vessels were pulled according to the contrasted tomography (Figure 1c, 1d). A renogram showed that the effective renal plasma flow (ERPF) was $166.03 \mathrm{ml} / \mathrm{min}$. Then the patient was prepared for surgical treatment and the procedure was performed in left lateral decubitus position. Under laparoscopy we found that the intestine herniated through the posterior margin of the liver. After reduction of the intestine, the right kidney was found in the hernia sac which was in transverse position with the renal hilum downward (Figure 2a, 2b). After adequate mobilization of the kidney, thoracoscopic exploration was performed under which a big defect in the right diaphragm and a hernia sac swelling into the thorax were presented. After reduction of the hernia sac, we could see the defect ranging from the medial costodiaphragmatic angle to the lateral that was primarily repaired with continuous suture (Figure 2c). At last, closure of the diaphragmatic hernia was confirmed under laparoscope and nephropexy was performed subsequently (Figure 2d). A chest drain was placed in the right hemithorax at the end of procedure that was removed after 48 hours. One week after operation, ultrasonography and contrasted tomography were 
reexamined and the results showed that the right kidney was in a normal position (Figure 3a, 3b) with a natural morphology and proper blood flow signal (Figure 3c, 3d). The baby had uneventful recovery and was discharged from the hospital on the postoperative day. Imaging examinations showed no abnormality in diaphragm after 3 and 12 months follow up and the effective renal plasma flow (ERPF) reached $202.96 \mathrm{ml} /$ min with an increase in the right kidney.

\section{Discussion}

ITK appears a male predominance and usually involves left side, which is possibly attributed to earlier closure of pleura-peritoneal channel on the right side and the presence of the liver that acts as a physical barrier[9]. It can be classified into four groups: (1) pure ITK with intact diaphragm, (2) ITK with eventration of the diaphragm, (3) ITK with congenital or acquired diaphragmatic hernia, and (4) traumatic diaphragmatic rupture and intrathoracic renal herniation[9]. The boy in our case had a right-side ITK associated with CDH.

Embryologically, the kidneys ascend from the pelvis at 5 weeks of gestion and reach the normal location in the renal fossa at 8-weeks. Meanwhile, the diaphragmatic leaflets develop to be a pleuroperitoneal membrane that separates the pleural cavity from the peritoneal cavity at the end of the second month[2]. So, the possible mechanism of ITK with $\mathrm{CDH}$ is thought to be excessive ascent of the kidney due to delayed closure the pleuroperitoneal membrane[10]. Another hypothesis is that the delayed ingrowth of the ureter into the metanephros brings about prolongation of the ascending process and a long ureter[2]. Other anatomical abnormalities may present as rotational abnormality, high renal vessel origin and medial deviation of the lower pole of the kidney[11].

Most patients with ITK are asymptomatic because the ectopic kidneys are usually functioning normally and do not lead to obvious symptoms[12]. Thus, it is usually asymptomatic and is discovered incidentally[9]. In a few cases, it may present as respiratory distress $[13,14]$. If suspected, the ITK can be confirmed by imaging methods such as chest radiograph, sonography, computed tomography, MRI and IVP[15, 16]. Besides, the renogram is helpful to define the function of ectopic kidney and is of positive significance to the diagnosis and treatment[6]. In some prenatally diagnosed cases, sonography plays an important role[17-19]. And the prenatal diagnosis of ITK can be made as early as 22 weeks of gestation according to existing reports[17]. It should be mainly differentiated from renal agenesis and thoracic masses, such as infectious diseases and neoplasms[12].

Although isolated and asymptomatic ITK usually doesn't require any treatment, ITK associated with CDH needs surgery due to the risk of respiratory distress and bowel suffering[18]. As ITK associated with CDH involves both thoracic cavity and abdominal cavity, so the approach of operation is variable. The diaphragmatic hernia can be safely and effectively repaired by different approaches[20]. Transthoracic approach provides wide exposure, better visualization of the diaphragmatic foramen and adhesions as well as better access to the hernia sac. It is frequently used in right-sided diaphragmatic hernia because of the presence of the liver[11] and in patients with severe adhesion[21]. Transabdominal approach makes it easy to reduce the hernia content and repair the sac and it is suitable for complicated hernias and that with abdominal complications[22]. Laparoscopic and thoracoscopic approaches provide the equal effectiveness compared with open repair, meanwhile, have all the advantages of minimal invasive surgery including 
reduction in trauma, fast recovery, minimal postoperative complication and shortened postoperative stay[3, 23]. Laparoscopic approach was first adopted by Van der Zee in 1995[24]. Currently, thoracoscopic approach is more preferred than laparoscopic approach for repair of $\mathrm{CDH}[25]$. Besides, thoracoscopic approach provides extrathoracic ligation as an alternative method and allows the surgeon to make a proper incision and precise repair[21].

However, controversy still remains concerning the management of the ectopic kidney. A few surgeons only reduced other contents into the abdominal cavity without handling the kidney[12], while others preferred to mobilize the ITK into abdomen and place it in a near-normal site[3, 5, 11, 18]. Pindoria et al hold the view that the primary concern is to restore the anatomical position of kidney in case of renal unit migration[26]. Besides, nephropexy is advocated by some surgeons[10,26]. For nephropexy, laparoscopic or robotic assisted laparoscopic approach has the advantages of reducing postoperative pain, shortening recovery time and hospitalization time[26, 27].

In our case, we firstly identified the origin of the renal vessels and ureters in order to avoid injury and fully free the kidney under laparoscope. Then we repaired the right-sided diaphragmatic hernia by thoracoscopic approach. Besides, we were in favor of nephropexy as the restoration of anatomic position is the key to function preservation and prevention of long-term renal damage. Thus, we decided to perform nephropexy through laparoscopic approach after hernia repair. The operation was successful and the recovery was satisfactory. Although combined thoracoscopic and laparoscopic approach has been used in treatment of complicated diaphragmatic hernia in adult patients[28,29], it is the first time that it has been applied in diaphragmatic hernia repair and nephropexy in a child who suffered from ITK associated with CDH.

\section{Conclusion}

We conclude that ITK associated with $\mathrm{CDH}$ in children is a rare entity that can be safely and effectively treated by different surgical approaches. Combined thoracoscopic and laparoscopic approach, which is minimally invasive, provided better visualization of the diaphragmatic foramen and the hernia sac, and could achieve anatomical reposition and fixation of the ectopic kidney.

\section{Abbreviations}

\section{ITK}

intrathoracic kidney

$\mathrm{CDH}$

congenital diaphragmatic hernia

\section{Declarations}

\section{Consent}

Written informed consent was obtained from the patient's parents for the publication of this report.

\section{Author Contributions}


$\mathrm{HX}$ had primary responsibility in treating the patient and manuscript review.

MMY participated in patient treatment and was responsible for writing the manuscript.

FC participated was responsible for manuscript review.

SSW participated in patient evaluation and treatment.

\section{References}

1. Masturzo B, Kalache KD, Cockell A, Pierro A, Rodeck CH: Prenatal diagnosis of an ectopic intrathoracic kidney in right-sided congenital diaphragmatic hernia using color Doppler ultrasonography. Ultrasound Obstet Gynecol. 2001; 18 (2): 173-174.

2. Donat SM, Donat PE: Intrathoracic kidney: a case report with a review of the world literature. J Urol. 1988; 140 (1): 131-133.

3. Mizzi C, Farrugia D, Choudhry MS: Congenital Diaphragmatic Hernia with Intrathoracic Renal Ectopia: Thoracoscopic Approach for a Complete Anatomical Repair. European J Pediatr Surg Rep. 2020; 8 (1): e74e76.

4. Boo YJ, Rohleder S, Muensterer OJ: A Novel Technique of Posterolateral Suturing in Thoracoscopic Diaphragmatic Hernia Repair. European J Pediatr Surg Rep. 2017; 5 (1): e26-e28.

5. Ben Dhaou M, Zouari M, Mhiri R: Congenital diaphragmatic hernia with intrathoracic kidney: unusual presentation. Asian Cardiovasc Thorac Ann. 2017; 25 (5): 403.

6. Padma S, Pande SR, Sundaram PS: (99m)Tc DTPA renogram indentifies Bochdalek hernia with an intra thoracic kidney as its content. World J Nucl Med. 2014; 13 (3): 193-196.

7. Kawashima S, Urushihara N, Fukumoto K: Laparoscopic repair of Bochdalek hernia with intrathoracic kidney in a 2-year-old child. Asian J Endosc Surg. 2014; 7 (3): 279-281.

8. Tillig B, Creutzfeldt R, Möritz RP: Intrathoracic kidney associated with congenital diaphragmatic hernia - a causal relationship? Eur J Pediatr Surg. 2009; 19 (4): 263-265.

9. Singh C, Shahnaz G, Handa R, Gupta NP, Sundar J: A missing kidney and a hidden congenital diaphragmatic hernia. J Clin Ultrasound. 2021; 49 (4): 401-404.

10. Murphy JJ, Altit G, Zerhouni S: The intrathoracic kidney: should we fix it? J Pediatr Surg. 2012; 47 (5): 970-973.

11. Karaoglanoglu N, Turkyilmaz A, Eroglu A, Alici HA: Right-sided Bochdalek hernia with intrathoracic kidney. Pediatr Surg Int. 2006; 22 (12): 1029-1031.

12. Rattan KN, Rohilla S, Narang R, Rattan SK, Maggu S, Dhaulakhandi DB: Thoracic kidney associated with congenital diaphragmatic hernia. Congenit Anom (Kyoto). 2009; 49 (3): 118-120. 
13. Keles S, Artac H, Elmaci M, Reisli I, Dilsiz A: Late-presenting congenital diaphragmatic hernia associated with ectopic thoracic kidney. Eur J Pediatr. 2006; 165 (8): 571-572.

14. Sesia SB, Haecker FM: Late-presenting diaphragmatic hernia associated with intrathoracic kidney: tachypnoea as unique clinical sign. BMJ Case Rep. 2012; 2012

15. Fiaschetti V, Velari L, Gaspari E, Mastrangeli R, Simonetti G: Adult intra-thoracic kidney: a case report of bochdalek hernia. Case Rep Med. 2010; 2010

16. Maduekwe E, Weinberg B, Samaan B, Sheferaw E, Suntharos P: Right thoracic ectopic kidney in a child with breathing difficulties--sonographic diagnosis. J Clin Ultrasound. 2011; 39 (2): 108-110.

17. Athanasiadis AP, Zafrakas M, Arnaoutoglou C, Karavida A, Papasozomenou P, Tarlatzis BC: Prenatal diagnosis of thoracic kidney in the 2nd trimester with delayed manifestation of associated diaphragmatic hernia. J Clin Ultrasound. 2011; 39 (4): 221-224.

18. Juricic M, Cambon Z, Baunin C, Abbo O, Puget C, Crouzet $\mathrm{K}$, et al.: Prenatal diagnosis of right-sided diaphragmatic hernia and ipsilateral intrathoracic kidney in a female fetus: a rare observation. Surg Radiol Anat. 2016; 38 (4): 419-423.

19. Panda B, Rosenberg V, Cornfeld D, Stiller R: Prenatal diagnosis of ectopic intrathoracic kidney in a fetus with a left diaphragmatic hernia. J Clin Ultrasound. 2009; 37 (1): 47-49.

20. Pfannschmidt J, Hoffmann H, Dienemann H: Morgagni hernia in adults: results in 7 patients. Scand $\mathrm{J}$ Surg. 2004; 93 (1): 77-81.

21. Nakashima S, Watanabe A, Hashimoto M, Mishina T, Obama T, Higami T: Advantages of videoassisted thoracoscopic surgery for adult congenital hernia with severe adhesion: report of two cases. Ann Thorac Cardiovasc Surg. 2011; 17 (2): 185-189.

22. Yilmaz M, Isik B, Coban S, Sogutlu G, Ara C, Kirimlioglu V, et al.: Transabdominal approach in the surgical management of Morgagni hernia. Surg Today. 2007; 37 (1): 9-13.

23. Yavuz N, Yiğitbasi R, Sunamak O, As A, Oral C, Erguney S: Laparoscopic repair of Morgagni hernia. Surg Laparosc Endosc Percutan Tech. 2006; 16 (3): 173-176.

24. van der Zee DC, Bax NM: Laparoscopic repair of congenital diaphragmatic hernia in a 6-month-old child. Surg Endosc. 1995; 9 (9): 1001-1003.

25. Jain V, Agarwala S, Bhatnagar V: Recent advances in the management of congenital diaphragmatic hernia. Indian J Pediatr. 2010; 77 (6): 673-678.

26. Pindoria N, Makanjuola J, Botha A, Nair R, Thurairaja R: "What Goes Up Must Come Down": Laparoscopic Retrieval of a Migrated Intrathoracic Kidney and Repair of Recurrent Symptomatic Diaphragmatic Hernia. J Endourol Case Rep. 2018; 4 (1): 129-132. 
27. Chen B, Finnerty BM, Schamberg NJ, Watkins AC, DelPizzo J, Zarnegar R: Transabdominal robotic repair of a congenital right diaphragmatic hernia containing an intrathoracic kidney: a case report. $J$ Robot Surg. 2015; 9 (4): 357-360.

28. Esmer D, Alvarez-Tostado J, Alfaro A, Carmona R, Salas M: Thoracoscopic and laparoscopic repair of complicated Bochdalek hernia in adult. Hernia. 2008; 12 (3): 307-309.

29. Gandhi S, Bhandarwar A, Sadhwani N, Patel C, Wagh A, Arora E: Combined laparoscopic and thoracoscopic approach for tension gastrothorax in a foramen of Bochdalek hernia. Int J Surg Case Rep. 2019; 65 141-147.

\section{Figures}
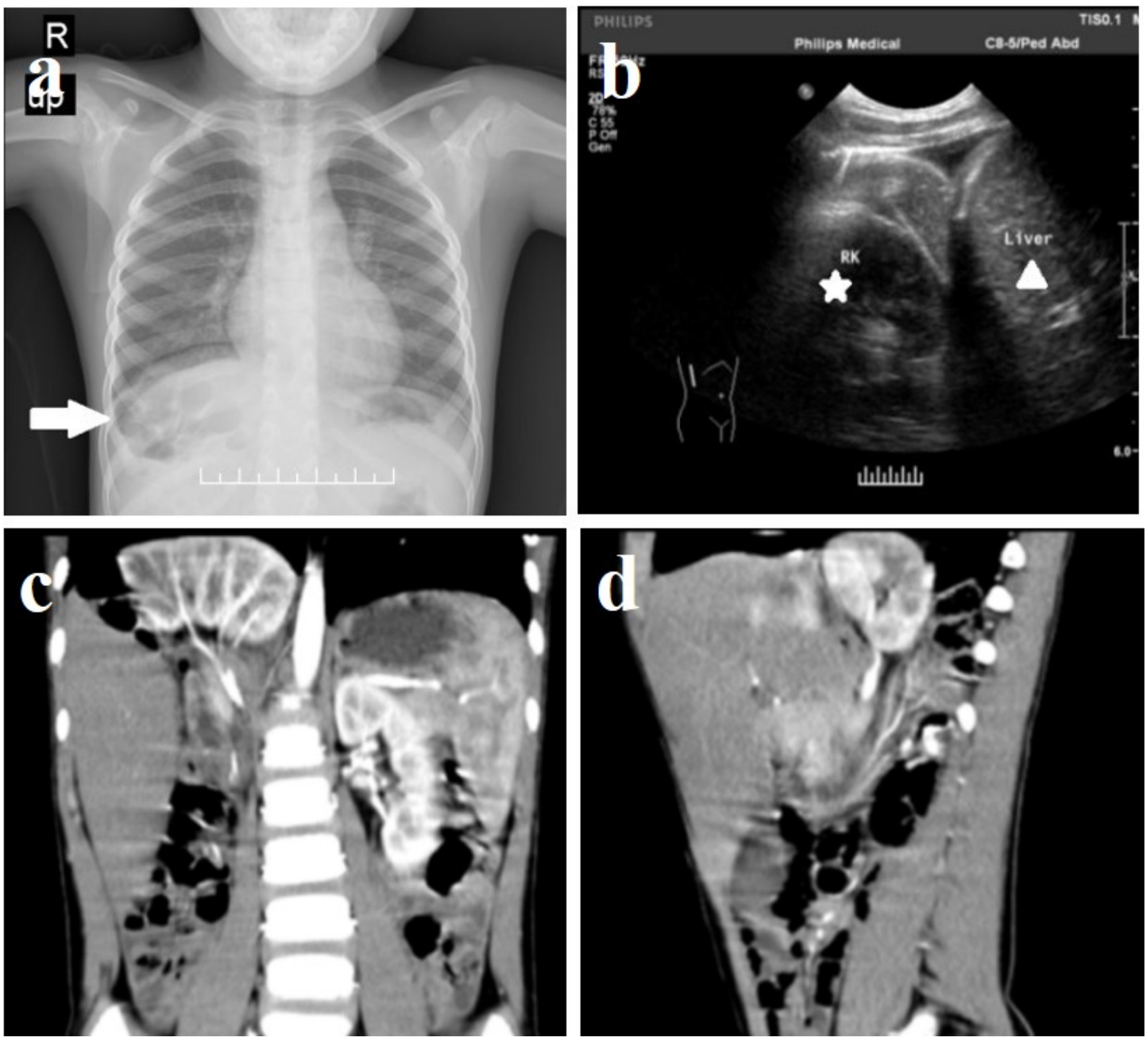


\section{Figure 1}

Imaging examinations before surgery. (a) Chest radiography revealed gas density shadows (white arrow) under the diaphragm. (b) Ultrasonography showed that the right kidney and part of the intestine herniated into the thoracic cavity. RK: right kidney. (c, d) Contrasted tomography demonstrated that the right kidney and part of the intestine were located under the right diaphragm. The right kidney was transposed with the renal hilum downward and the renal vessels were pulled.
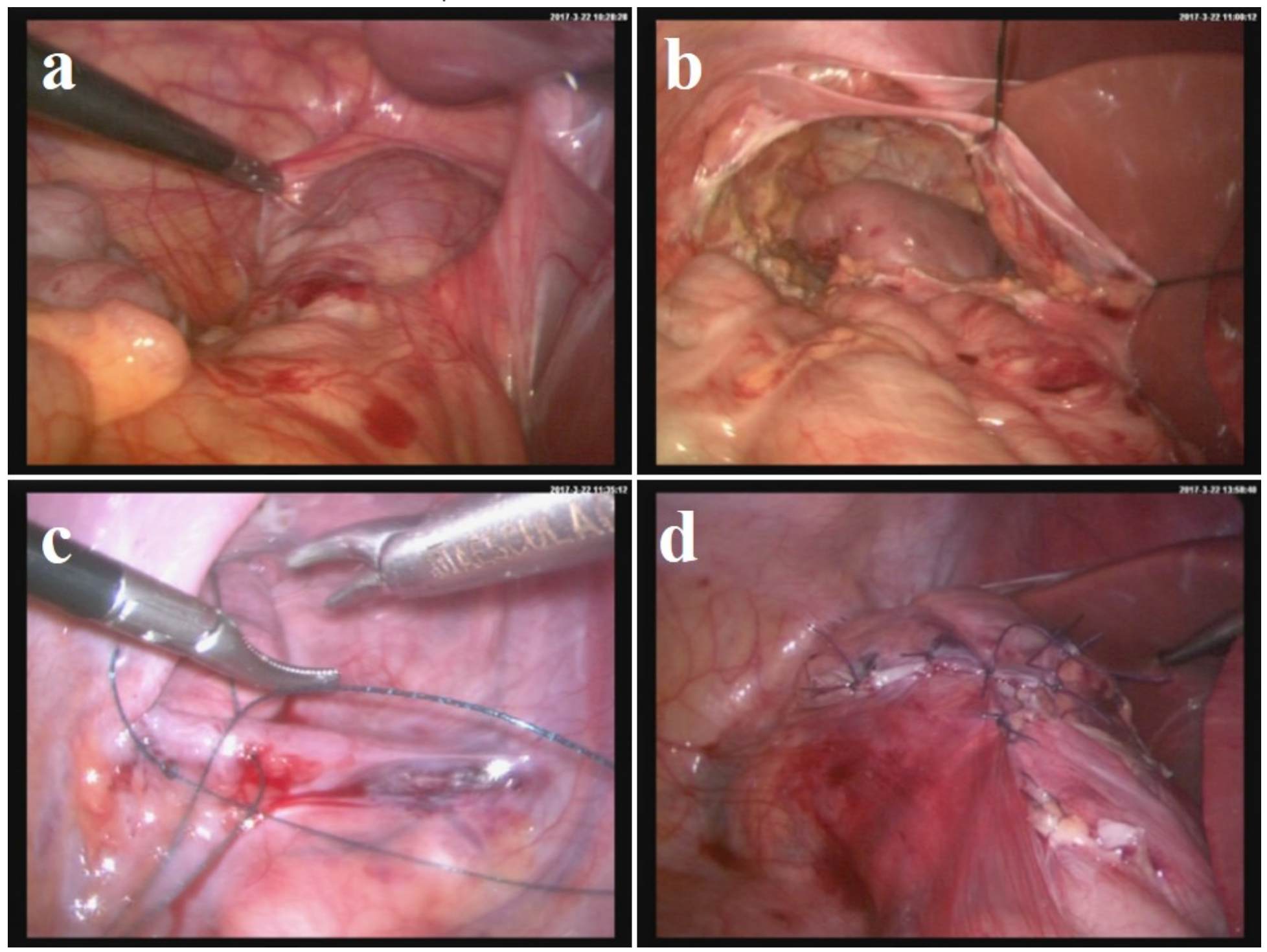

\section{Figure 2}

Surgical treatment was performed through combined thoracoscopic and laparoscopic approach. (a) During laparoscopic exploration, the right kidney was found located behind the liver after pulling the intestine downwards. (b) The liver was suspended and the right kidney was fully exposed and released. (c) The diaphragmatic hernia was repaired under thoracoscopy. (d) The kidney was fixed in the renal fossa with retroperitoneal embedding under laparoscopy. 

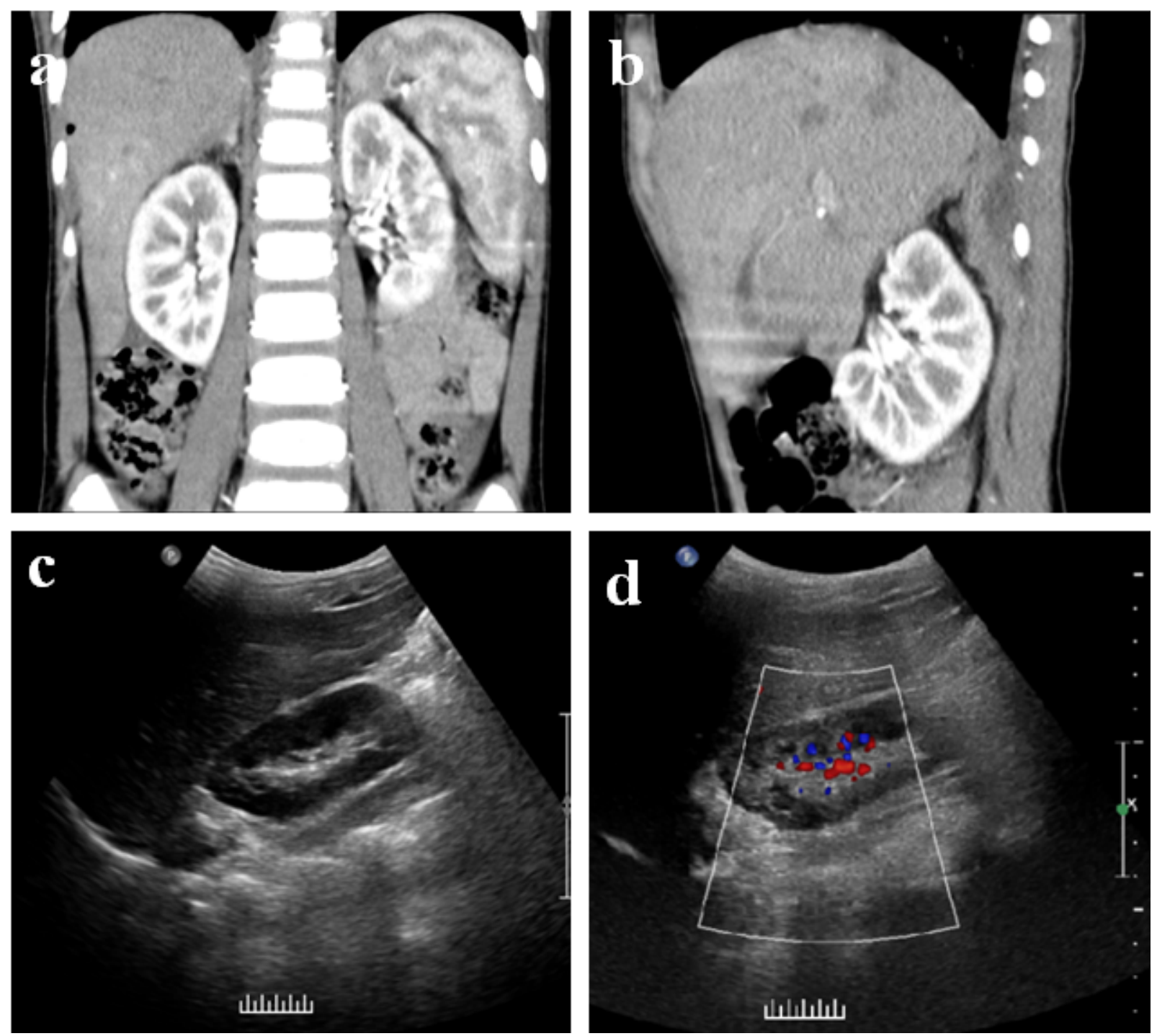

\section{Figure 3}

Contrasted tomography and ultrasonography of the kidney at 1 week postoperatively. $(a, b)$ Contrasted tomography revealed that the right kidney was in a normal position without rotation. (c, d) Ultrasonography showed a normal morphology of the right kidney with proper blood flow signals. 